\title{
Repensando a gestão editorial de periódico acadêmico no campo da Administração
}

ANA LUCIA GUEDES ${ }^{1}$

\author{
${ }^{1}$ Fundação Getulio Vargas / Diretoria de Análise de Políticas Públicas, Rio de JaneIRo - RJ, Brasil
}

\section{Resumo}

Este artigo descreve o histórico da criação do periódico Cadernos EBAPE.BR para destacar sua evolução, em termos de gestão editorial, no período de junho de 2009 a dezembro de 2012. Ao questionar como o Cadernos EBAPE.BR contribui com o estudo da Administração, acabo por refletir acerca do papel dos periódicos acadêmicos e dos correspondentes desafios editoriais diante da elevada pressão institucional por produção acadêmica publicada.

Palavras-chave: Gestão Editorial. Periódico Acadêmico. Administração.

\section{Rethinking the editorial management of academic journal in the Administration field}

\section{Abstract}

This article describes the history of the establishment of Journal Cadernos EBAPE.BR in order to highlight its evolution, in terms of editorial management, in the period from June 2009 to December 2012. Grounded on the issue of how Cadernos EBAPE.BR contributes to the study of Administration, I reflect about the role of academic journals and the corresponding editorial challenges in the face of the growing institutional pressure to publish academic production.

Keywords: Editorial Management. Academic Journals. Administration.

\section{Repensando la gestión editorial del periódico académico en el campo de la Administración}

\section{Resumen}

En este artículo se describe el historial del periódico Cadernos EBAPE.BR para destacar su evolución en términos de gestión editorial, en el período de junio de 2009 a diciembre de 2012. Al cuestionar cómo Cadernos EBAPE.BR contribuye al estudio de la Administración, reflexiono sobre el papel de los periódicos académicos y de los correspondientes desafíos editoriales ante la elevada presión institucional para la publicación de producción académica.

Palabras clave: Gestión editorial. Periódico académico. Administración. 


\section{CONTEXTUALIZAÇÃo}

Como o periódico Cadernos EBAPE.BR contribui para o estudo da Administração? Com este questionamento, tomo a liberdade de escrever um artigo menos formal (do que poderia ser um ensaio) para oferecer uma narrativa confessional (VAN MAANEN, 2011), pela recontagem de experiências e/ou pela releitura de um passado particular. Entendo que, dessa forma, atendo melhor ao convite para participar do relevante debate promovido por esta edição especial do Cadernos EBAPE.BR dedicada à história da editoria científica em Administração no Brasil.

Dentre minhas razões para fazer confissões, eu poderia listar a ausência de textos (e chamadas) focados em gestão editorial na área de Administração no Brasil e de preocupação da comunidade acadêmica com a "cozinha" da gestão editorial e com práticas das quais queremos nos livrar para sermos mais científicos em um campo sempre sob suspeita - ou, ainda, a expectativa de produzir algum impacto (em certo ativismo intelectual) (cf. CONTU, 2018).

Apesar da experiência editorial, que não está dissociada da formação e da prática acadêmica, eu preciso justificar porque esta narrativa faz sentido. Alunos de pós-graduação, ao lerem este artigo, porque será disponibilizado a eles, lembrarão debates acalorados focados nos tipos de narrativas dos artigos selecionados, principalmente quando identificávamos, em conjunto, os vieses das políticas editoriais dos principais periódicos (nacionais e internacionais) da área. Na experiência docente em seminário de pesquisa, os alunos percebem que identificar as narrativas requer conhecimento (portanto, leituras) epistemológico e metodológico. Isso implica que tal conteúdo esteja acessível e seja desmitificado nos programas de pós-graduação por meio de leitura e debate de publicações nos periódicos da área.

Um exemplo seria a adoção, como leitura complementar, do artigo de Paes de Paula (2016), publicado no Cadernos EBAPE.BR. O texto, que reflete as angústias da autora, contribui com o debate acerca das disputas epistêmicas em Estudos Organizacionais. Ao situarmos os autores e as respectivas produções dentro do que seriam os parâmetros estáticos do modelo proposto, os alunos avançam no âmbito negligenciado, nos programas de pós-graduação, da sociologia do conhecimento. Compreendem melhor quem são esses pesquisadores que compõem a comunidade acadêmica, como se comportam ao assumirem posições de coordenadores de áreas nos congressos e/ou de editores, avaliadores e autores de artigos e, principalmente, como são as disputas epistêmicas correspondentes.

Em paralelo, um periódico contribui para informar, com base na devida e contínua revisão da literatura, os desdobramentos teórico-metodológicos de determinadas abordagens para a compreensão e/ou explicação de complexos fenômenos sociais, organizacionais, individuais. Essa prática acadêmica acaba distanciando o periódico e/ou o debate proposto da realidade (CALÁS e SMIRCICH, 2013). Apropriamo-nos (in)devidamente dessa realidade sem problematizar como estamos inseridos e como somos consumidos pelos leitores. Afinal, o que é contribuir com os estudos em Administração sem uma problematização do que é o campo da Administração e o da editoração científica?

Outra razão para adotar esta narrativa confessional decorre da minha recente interrupção voluntária das atividades junto à pós-graduação stricto sensu, no que deveria ter sido um ano sabático, que resultou em reflexões de natureza prática quanto ao papel da academia e da produção acadêmica destituída de significado e, principalmente, de impacto. Sem tempo, nem espaço, para descrever detalhadamente, assumo todos os meus vieses para o que denomino significado e impacto. Ciente de que receberei críticas por nunca ter sido crítica o bastante para transitar nesses domínios.

Pois bem, o desafio de produzir pesquisa aplicada provocou reflexões acerca da distância entre o que leio, ensino e escrevo para as potenciais implicações políticas, sociais e organizacionais dessa mesma produção acadêmica. Esse processo requer muitas edições e revisões para resultar em uma narrativa que faça sentido para os leitores. Indago, portanto, o quê e para quem estamos escrevendo? Periódicos e pesquisadores devem produzir impacto social sem que o devido debate quanto ao impacto dessa realidade sobre os periódicos e pesquisadores tenha sido problematizado. Por que nós, como produtores e consumidores de conhecimento acadêmico, não podemos problematizar esses impactos? Por que nos afastamos dos praticantes, formuladores de políticas, representantes das indústrias editorial e educacional? A quem "impacto" serve ou deve servir?

Precisamos repensar a relação entre a produção e a publicação de tal modo que os impactos sejam mais explícitos e os periódicos acadêmicos possam ser espaços que privilegiem a reflexão e o debate de temas, abordagens, que reflitam a complexidade e pluralidade dos fenômenos que tanto nos fascinam, para múltiplas audiências. 
O Cadernos EBAPE.BR tem, ao longo da sua trajetória singular, contribuído para o debate na área de Administração inclusive no que se refere à sua própria inserção no âmbito da economia política da produção do conhecimento. Ao privilegiar outra abordagem, diante do que se denominava, em 2003, mainstream na Administração e, talvez, por aceitar a submissão de distintas narrativas, na forma de ensaios, manifestos e resenhas, além dos artigos teórico-empíricos que resultam de pesquisas de caráter qualitativo. O relato que apresento, a seguir, propõe-se a resgatar a narrativa daqueles que conduziram esse processo de institucionalização do periódico em sua versão on-line.

\section{A CRIAÇÃO DO CADERNOS EBAPE.BR}

No histórico do Cadernos EBAPE.BR (FGV, 2017) constam os depoimentos do então Diretor da Escola Brasileira de Administração Pública e de Empresas da Fundação Getulio Vargas (FGV EBAPE), Bianor Cavalcanti, e do Editor Marcelo Milano Falcão Vieira, que relatam como o nome Cadernos EBAPE.BR foi escolhido como "expressão simbólica" do pioneirismo no estudo da Administração no Brasil, em referência à série Cadernos de Administração Pública, publicada de 1954 até 1971 , que consistia em uma:

[...] série de livros, de textos, monografias e casos especialmente elaborados para o programa de pesquisas sobre Administração Pública brasileira, expressão de convênio entre a FGV e a Fundação Ford, [que] defendeu em larga medida o ensino no campo disciplinar que, como tal, se instalava no país (FGV, 2017).

A nova série, intitulada Cadernos EBAP, foi retomada em 1980 e sua última publicação saiu em 2002:

[...] esta série, mais modesta em seu projeto gráfico-editorial, [estimula] a circulação de ideias entre professores e alunos da Escola, bem como entre os membros da comunidade acadêmica na área de Administração e [divulga], em caráter preliminar, mais restrito, trabalhos acadêmicos e resultantes de consultorias para órgãos públicos e empresas (FGV, 2017).

Em 2003, Marcelo Milano Falcão Vieira (Editor de 2003 a 2009) assumiu a missão de revitalizar a série Cadernos EBAP, que era publicada em forma impressa, e proporcionar à comunidade acadêmica na área de Administração algo inovador no Brasil:

[...] decidimos por adotar uma linha que clara e explicitamente privilegiasse ensaios teóricos e pesquisas qualitativas, visto que à época nossa comunidade ainda estava sob forte influência positivista, quantitativa (FGV, 2017).

O periódico on-line teve início com a publicação de três números anuais de autoria de pesquisadores brasileiros e estrangeiros. A aceitação da revista no meio acadêmico foi imediata, porque o Editor adotou um rigoroso processo de mesclar os artigos regularmente submetidos e avaliados a artigos de autores convidados que refletiam o espírito da política editorial. Assim, conseguiu institucionalizar o escopo e a política de promover o debate de temas relevantes para a construção do conhecimento no âmbito da Administração com base em abordagens interdisciplinares e críticas - iniciativa prontamente reconhecida pela comunidade acadêmica no Brasil.

Em 2009, após seis anos como editor-chefe, e muitos esforços para inserir o Cadernos EBAPE.BR em bases de indexação e classificação, havia consolidado o periódico na comunidade acadêmica da área.

Em junho de 2009, fui consultada pelo editor-chefe do Cadernos EBAPE.BR e pelo Diretor da EBAPE, Flavio de Vasconcelos, quanto ao meu interesse e minha disponibilidade para assumir a editoria do periódico, com o propósito de dar continuidade ao trabalho desenvolvido pela equipe editorial (FGV, 2017). Aqueles que tiveram o privilégio de conviver com Marcelo Milano Falcão Vieira podem testemunhar o quanto este projeto editorial Ihe era caro. Sua dedicação ao Cadernos EBAPE.BR estava evidente nos detalhes do processo editorial artesanal. Um marco importante nesse momento foi a indexação do periódico na base Scientific Electronic Library Online (SCIELO).

Acompanhei por um período de seis meses, em um interessante processo de socialização, a alocação das pautas e elaboramos em conjunto os editoriais (GUEDES e VIEIRA, 2009). Nosso compromisso foi manter inalterada a política editorial e o escopo 
interdisciplinar e crítico. Relato, a seguir, alguns aspectos da gestão editorial do periódico durante o mandato efetivamente cumprido, de janeiro de 2010 a dezembro de 2012 (GUEDES, 2010, 2011, 2012a, 2012b).

\section{EVOLUÇÃO DO MANDATO}

O número 4 de 2009 do Cadernos EBAPE.BR simboliza a bem orquestrada transição editorial, conduzida por Marcelo Milano Falcão Vieira. Reiteramos, em conjunto, a missão do periódico de promover debates em diferentes âmbitos da Administração Pública e de Empresas, por meio de abordagem editorial fundamentada na interdisciplinaridade e na reflexão crítica, particularmente comprometida com o desenvolvimento teórico-conceitual da área de Administração no (e a partir do) Brasil.

Ao longo desse mandato, o Cadernos EBAPE.BR passou por profundas alterações em suas práticas editoriais, com o propósito de elevar a visibilidade e a reputação do periódico junto à comunidade acadêmica da Administração. Em face da transição para o sistema de submissão on-line da SciELO, em 20 de maio de 2010, que visava a conferir transparência ao processo editorial, o periódico enfrentou o desafio de gerenciar um elevado número de submissões.

O fato da equipe editorial ser constituída por uma bolsista, em tempo parcial, levou-nos à adoção do controverso (por não ser prática corrente nos periódicos do Brasil) procedimento de rejeição editorial como primeira etapa após a submissão. Essa medida gerou uma profusão de telefonemas e mensagens de autores e avaliadores, no entanto, em poucos meses, permitiu que melhorássemos a qualidade das cartas editoriais.

Em paralelo, intensificamos os esforços de internacionalização do periódico, com a renovação do Conselho Editorial e o apelo à submissão de artigos em outros idiomas. A revisão das normas de submissão do periódico, de acordo com as Boas Práticas da Associação Nacional de Programa de Pós-Graduação em Administração (Anpad), resultou em inúmeras manifestações (contrárias e favoráveis) por parte de autores e membros do Corpo Editorial.

Ao longo desse processo, a página que hospedava o Cadernos EBAPE.BR no Portal FGV EBAPE foi revisada inúmeras vezes, foram adotadas regras para os revisores de idioma e um formato e novo layout na fase de diagramação dos artigos, para aprimorar sua apresentação eletrônica e impressa.

A inclusão do Cadernos EBAPE.BR na base de periódicos em português - Fonte Acadêmica - da EBSCO sustentou, no primeiro trimestre de 2011, a proposta editorial de ampliar o escopo de divulgação e acesso para o público acadêmico no exterior.

Outro desafio importante foi o projeto de digitalização, conversão e marcação de 25 fascículos retrospectivos do Cadernos EBAPE.BR, publicados entre 2003 e 2009, para veiculação na base de indexação do SciELO, com atribuição de digital object identifier (DOI). O custo dessa iniciativa foi justificado, junto à Direção da EBAPE, com o argumento da ampliação do impacto do periódico nas bases de indexação e classificação.

Ao final do mandato, executamos o projeto de inclusão do periódico em um novo host (na Biblioteca Digital do Portal FGV), visando à utilização de novas ferramentas no processo de submissão, avaliação e publicação dos artigos, ao fácil acesso e cadastramento de leitores e autores, bem como para atender às demandas específicas das indexações. Esses compromissos foram cumpridos com apoio institucional recebido da FGV e com proposta de editoração financiada pelo Conselho Nacional de Desenvolvimento Científico e Tecnológico (CNPq).

A parte prazerosa das atividades editoriais fica registrada nas mensagens de apoio dos autores, dos avaliadores e dos editores (associados e/ou convidados), mas, também, na elaboração e publicação das chamadas de trabalhos para os números temáticos "Echoes of LAEMOS (Latin American and European Meeting on Organization Studies)" e "Interfaces Público-Privado no Contexto Luso-Brasileiro", em 2010; "Gestão Social: Ensino, Pesquisa e Prática" e a edição especial de "Ensino e Pesquisa em Administração", em 2011. O número temático “Rio+20", em 2012, e as chamadas dos números temáticos “DevelopmentManagement/Development\&Management", em 2013, e "Management Industry", com publicação em março de 2014. Todas essas chamadas refletem minhas preferências nas tentativas de produzir significado e impacto, mas também ilustram que a gestão editorial transborda o mandato (PATRIOTTA e GUEDES, 2010). 
Como parte dos esforços de gerar impacto, foram incentivadas contribuições para a Seção Opinião, para manter o privilegiado espaço de debate acerca de temas relevantes para a comunidade acadêmica da Administração. Novamente, os temas refletem meus vieses e preferências.

É importante registrar a criação da posição de editor associado para as seguintes áreas: Estudos Críticos; Estudos Organizacionais; Estudos em Marketing e Estudos em Estratégia. Reconheço publicamente a importância de compartilhar as responsabilidades, principalmente na difícil tarefa de revisão editorial e nas indicações dos avaliadores.

Essa decisão, com apoio da Direção da FGV EBAPE, tampouco esteve livre de críticas veladas, que foram desveladas ao longo do tempo, quanto às minhas preferências editoriais. Ampliar o escopo editorial do Cadernos EBAPE.BR, com uma editora com formação em Administração e Relações Internacionais, parecia ameaçador para alguns autores e membros do Conselho Editorial.

O número 4 de 2012, publicado em dezembro, representa o fim do meu mandato como Editora do Cadernos EBAPE.BR. Os desafios foram superados com apoio da equipe editorial institucionalizada que assumia, em paralelo, atividades editoriais da Revista de Administração Pública (RAP), da FGV EBAPE. Entendo ter cumprido, nas palavras de Marcelo Milano Falcão Vieira, "uma transição tranquila e equilibrada", apesar de todas as turbulências institucionais. Ao final, tive a impressão de que o Cadernos EBAPE.BR havia exercido a potencialidade de sua missão editorial com a valiosa (e voluntária) contribuição dos membros do Conselho Editorial.

\section{REVISTAS CIENTÍFICAS NO CAMPO DA ADMINISTRAÇÃO NO BRASIL}

Esta reflexão final poderia iniciar-se com a descrição dos parâmetros em vigor para avaliação de periódicos. Cadernos EBAPE.BR se encontrava no estrato B2 do Qualis da Coordenação de Aperfeiçoamento de Pessoal de Nível Superior (Capes) em 2009, transitou pelo estrato B1 no triênio 2010-2012 e atingiu o estrato A2 no quadriênio 2013-2016. Porém, em paralelo aos critérios da comissão de avaliação do Qualis da Capes, os periódicos nacionais são pressionados para adotar os parâmetros das Boas Práticas da Anpad e dos indexadores nacionais e internacionais.

Mais recentemente, a crescente influência das editoras internacionais na Capes e no Ministério da Educação (MEC), bem como na gestão dos principais periódicos da área, inclusive na editoração e nas equipes editoriais, levou a SciELO a um questionamento público no Brasil que parece ter sido deslocado para os bastidores da editoria acadêmica.

A permanente pressão por internacionalização, desde as soluções dos autores custearem as traduções dos artigos até a submissão exclusiva em inglês, não tem sido debatida pela comunidade acadêmica em fórum aberto.

Os editores deveriam promover um debate mais amplo que leve em consideração a área de Administração e a gestão editorial no século XXI. Preferencialmente para acomodar a necessária internacionalização sem perder de vista o escopo nacional de temas, âmbitos ou subáreas. Estaríamos escrevendo e publicando para sermos lidos e citados pelos pares nacionais e estrangeiros, mas, também, pelos praticantes e/ou formuladores de políticas, se fossem resguardadas a pluralidade de narrativas com todos os seus vieses e significados.

Entretanto, qual editor optaria por permanecer no estrato B do Qualis da Capes, com acesso gratuito, para publicar, em português, artigos, ensaios, manifestos e resenhas? 


\section{REFERÊNCIAS}

CALÁS, M.; SMIRCICH, L. Organization@21 The journal of disconcerting organization theory and action. Organization, v. 20, n. 1, p. 13-24, 2013.

CONTU, A. '...The point is to change it' - Yes, but in what direction and how? Intellectual activism as a way of 'walking the talk' of critical work in business schools. Organization, [s. n], 2018. No prelo.

FUNDAÇÃO GETULIO VARGAS - FGV. Cadernos EBAPE.BR: histórico. 2017. Disponível em: <http://bibliotecadigital.fgv.br/ojs/index.php/ cadernosebape/pages/view/histórico>. Acesso em: 8 dez. 2017.

GUEDES, A. L. Editorial. Cadernos EBAPE.BR, v. 8, n. 1, 2010.

GUEDES, A. L. Editorial. Cadernos EBAPE.BR, v. 9, n. 1, 2011.
GUEDES, A. L. Editorial. Cadernos EBAPE.BR, v. 10, n. 1, 2012a.

GUEDES, A. L. Editorial. Cadernos EBAPE.BR, v. 10, n. 4, $2012 \mathrm{~b}$.

GUEDES, A. L.; VIEIRA, M. M. F. Cadernos EBAPE.BR, v. 7, n. 3, 2009.

PAES DE PAULA, A. P. Para além dos paradigmas nos estudos organizacionais: o círculo das matrizes epistêmicas. Cadernos EBAPE. BR, v. 14, n. 1, p. 24-46, 2016.

PATRIOTTA, G.; GUEDES, A. L. Editorial. Cadernos EBAPE.BR, v. 8, n. 2, 2010.

VAN MAANEN, J. Tales of the field: on writing ethnography. Chicago: University of Chicago Press, 2011. 